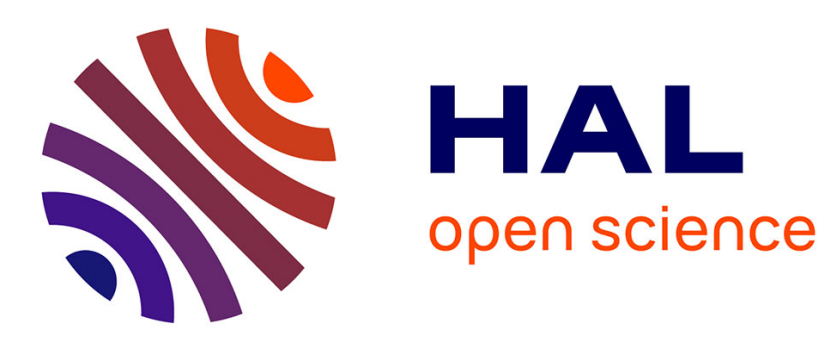

\title{
12. Comportement collectif de jonctions Josephson
}

\author{
H. Cortès, P. Pellau, J. Rosenblatt
}

\section{To cite this version:}

H. Cortès, P. Pellau, J. Rosenblatt. 12. Comportement collectif de jonctions Josephson. Revue de Physique Appliquée, 1970, 5 (6), pp.904-904. 10.1051/rphysap:0197000506090401 . jpa-00243482

\section{HAL Id: jpa-00243482 https://hal.science/jpa-00243482}

Submitted on 1 Jan 1970

HAL is a multi-disciplinary open access archive for the deposit and dissemination of scientific research documents, whether they are published or not. The documents may come from teaching and research institutions in France or abroad, or from public or private research centers.
L'archive ouverte pluridisciplinaire HAL, est destinée au dépôt et à la diffusion de documents scientifiques de niveau recherche, publiés ou non, émanant des établissements d'enseignement et de recherche français ou étrangers, des laboratoires publics ou privés. 


\section{COMPORTEMENT COLLECTIF DE JONCTIONS JOSEPHSON}

\section{H. CORTÈS, P. PELlaU et J. ROSENBLATT}

I. N. S. A., Rennes, France

Une collection de jonctions Josephson a été réalisée en pressant ensemble quelque $10^{4}$ grains supraconducteurs d'un diamètre moyen de $1 / 10^{\mathrm{e}}$ de millimètre. La résistance à polarisation nulle et le courant critique de ce système sont étudiés en fonction de la température et cette étude permet de définir une température critique inférieure à celle des grains isolés. 